\title{
FICÇÃO E AUTO/BIOGRAFIA: IMPLICAÇÕES TEÓRICAS ${ }^{1}$
}

\author{
Júnia de Castro Magalhães Alves*
}

RESUMO:

\begin{abstract}
Partindo de uma análise dialético-comparativa do processo de apropriação da história, através da memória, este estudo focalizará as dimensões referencial e representativa dos textos ficcionais e memorialísticos. 0 termo "história" será empregado em sentido amplo - como um conjunto de conhecimentos adquiridos através da tradição, de lendas e de contos elou por meio de documentos relativos à evolução, ao passado da humanidade, para salientar a idéia de que a ficçâo (narrativa derivada mais da fantasia do autor do que do fato) e a autobiografia apresentam inúmeras caracteristicas em comum $e$ objetivos convergentes, conforme defendem os teóricos da nova história.
\end{abstract}

PALAVRAS-Chave: Autobiografia, Memória, História, Ficção, Fato.

Em uma época em que a descrença da verdade histórica é axiomática, em que a morte do autor é propagada pelos teóricos do desconstrucionismo, do pósestruturalismo e do pós-modernismo, torna-se menos atraente o estudo das dimensões referencial e representativa do texto literário. Entretanto, é instigante trabalhar tais dimensões, a partir de uma análise dialĕtico-comparativa do processo da apropriação cultural da história para sua recriação, através da memória. A metodologia dialética permite o uso de um sistema de conceitos, onde cada tese (neste caso o fato) carrega inerentemente sua própria antítese (a reconstrução do fato), e onde os pontos opostos, ao se anularem, criam uma outra unidade-síntese (a ficção) que é, por sua vez, uma nova tese sujeita ao processo infinito de reconstrução, de revisão. Em sentido amplo, o método dialético engloba o discurso crítico dialógico bakhtiniano. Toda voz cultural, segundo

* Doutora em Literatura Comparada, 1996. 


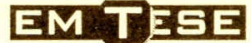

Belo Horizonte, V. I, p. I - 144, Dez. 1997

Bakhtin, coexiste em diálogo com outras vozes que, embora se reflitam mutuamente, não se fundem em uma consciência única e que, na verdade, geram entre si a energia de universos culturaịs relacionados. 0 dialogismo não se refere à heterogeneidade como tal, mas ao ângulo polifônico em que falas diferentes se justapõem e se contrapõem, de modo a produzir uma nova concepção, à semelhança da sintese hegeliana. 0 uso da teoria dialógica de Bakhtin propicia a percepção das ilimitadas possibilidades discursivas geradas pelo hábito retórico literário, chamando a atenção para a convivência da pluralidade de vozes que se reorganizam em momentos diferentes para a criação de uma nova variante do mesmo evento. Este trabalho quer avaliar como as modalidades literárias relacionam-se com o fato histórico, em um movimento que busca a reconstituição do passado individual e coletivo através da preservação pela memória. 0 texto propriamente dito (ou macrossigno) e também a suposta realidade (ou objeto) a que se refere servem para evidenciar processos de relacionamento entre literatura, auto/ biografia e historiografia - entre história, memória e ficção.

0 termo "história" é empregado aqui em sentido amplo - como um conjunto de conhecimentos adquiridos através da tradição, de lendas e contos e/ ou por meio dos documentos, relativos à evolução, ao passado da humanidade - para salientar a idéia de que a ficção (narrativa derivada mais da fantasia do autor do que do fato) e a história apresentam inúmeras características em comum e objetivos convergentes, conforme defende CERTEAU (1988), retomando a tradição da história nova e a perspectiva comparatista adotada pela revista Anais da História Econômica e Social e por pesquisadores contemporâneos, tais como Henri Berr, Henri Pirenne, Jacques Le Goff, Pierre Goubert, Nathan Wachtel, Paul Veyne, Alain Besançon, Fernand Braudei, Emmanuel Le Roy Ladurie e Hayden White, entre outros. A revista Anais (Annales), como é comumente referida, foi fundada em 1929 por Lucien Febvre e Marc Block, com o intuito de liberar a história de seu encarceramento em barreiras estritamente disciplinares. 0 movimento da new history, na verdade, surge nos Estados Unidos, em 1912, sendo primeiramente divulgado por H.E. Barnes com a publicação do livro Psychology and History, em 1919 e The New History and the Social Sciences, em 1925, onde se esboçam as linhas do referido movimento. A história nova sofre uma revolução documental no 
que se refere à crítica de arquivos e à percepção do tempo e das mudanças sócioeconômicas. Rejeita a narrativa simplista e arbitrária dos acontecimentos (a história historicizante, como explica Febvre) e envereda por uma análise mais eclética da multiplicidade de vozes e de motivos à procura de aprofundamento teórico, visando à desconstrução de conceitos superficiais calcificados, ao descentramento de poderes estabelecidos e ao reconhecimento de que cada história é uma pseudo-história, ou ainda, uma entre-históriaª no jogo dialógico e dialético da reconstituição do fato pelas diplomacias rivais. A conscientização de que toda narrativa é uma forma discursiva tendenciosa na representação dos acontecimentos dilui a distinçãu entre os discursos histórico e ficcional, na suposição da existência de uma diferença ontológica entre os respectivos referentes. Essa conscientização contém os subsídios indispensáveis para a análise aqui proposta.

0 conceito de memória, neste estudo, está 1 igado à idéia de mobilização e de performance, e não à de um conteúdo fixo. Para BHABHA (1990:304), performance sugere a perda da identidade no processo da identificação cultural e opõe-se a uma atitude pedagógica que propicia a crença na sedimentação histórica. Nesse sentido, a memória é a repetição do não-idêntico, embora ela emane sempre de um mesmo percurso. 0 termo memória implica tanto ausência como presença, ambas representadas pelo traço mnêmico freudiano, índice da presença de uma ausência. Sendo assim, o passado volta através da falta, isto é, através da impossibilidade de seu resgate. A memória não é o passado, mas sim um construto hipotético que o encadeia ao presente. Ela nasce do perdido. Memórias são, na terminologia de Hellman, pentimentos, isto é, restos recuperados, reencontrados ou reinventados, através de um processo não-linear do pensamento. A memória quebra a linearidade do tempo, distancia-se da experiência imediata e modifica o significado dos eventos através de novas interpretações. A escrita memorialística funciona, pois, como uma espécie de espelho que, a partir do indivíduo, reflete o grupo e a nação. De acordo com EAKIN (1988:21-47), a idéia do relacionamento entre história, biografia e identidade nacional surgiu com Wilhelm Dilthey, que concebeu a auto/biografia como a célula germinal da história. Em consonância com a concepção diltheyniana, o princípio que serve de base para relacionar criação 


\section{EM T코조}

Belo Horizonte, V. I, p. I - 144, Dez. 1997

literária, ato auto/biográfico e interpretação da história é a assertiva de que eles constituem embriões, isto é, unidades estruturais de apoio ou fundamento para a reconstrução ficcional da realidade. O auto/biógrafo é um escritorrelator, aparentemente autônomo, já que pretende modular sua própria identidade. 0 romancista recupera percepções pessoais e sociais, dando passos mais largos em direção à ficção. Toda história - pública ou privada, individual ou coletiva pressupõe um narrador (não necessariamente o autor) que, a partir de si mesmo, define ou redefine, infere ou inventa uma realidade social, inserida, como ele, em um contexto mais abrangente. Desta forma, o historiador produz a história ao mesmo tempo em que pertence a ela.

A escrita auto/biográfica procede do eu-narrador como representante, primeiramente, de si mesmo, e, ademais, da cultura em que se inclui, caminhando em direção ao desempenho de um papel histórico-ficcional. Como discutem filósofos e historiadores mais recentes, o "historicamente real" - istoé, aquilo que a história relata como fato verídico - é artefato, ou melhor, um produto manufaturado pelo próprio indivíduo. Assim sendo, os limites entre historiografia, auto/biografia e ficção esvanecem-se com a diluição das fronteiras que separam essas formas de escrita. Os gêneros entrelaçam-se, formando uma rede infinita e indefinível de relações que caminham em direção à aporia do pós-moderno.

Estudos contemporâneos que problematizam a lógica e a construção do mundo ficcional, e o seu contato com o "mundo real", freqüentemente favorecem a orientação pragmática da historiografia e da auto/biografia como imposições ou construções ideológicas. CERTEAU (1988), HALBWACHS (1990) e LEJEUNE (1989: 3-30, 119-137) entre outros, partem de uma base epistemológica comum, isto é, partem de princípios tradicionais que fundamentam o estudo das categorias em questão, para propor uma nova análise do relacionamento entre elas. As teorias por eles formuladas são complementares e podem ser utilizadas intertextualmente, para apontar as correspondências e a rede de significados que entrelaça ficção, memória e história. Outros teóricos da construção de mundos na literatura serão mencionados oportunamente, já que a epistemologia inclusiva desse tópico seria matéria, com certeza, inesgotável. 
CERTEAU (1988) alega que a mesma força que motiva o pensamento figurativo ou metafórico também modula a historiografia. 0 historiador descreve viagens imaginárias de volta no tempo, usando, cuidadosamente, um tipo de linguagem que propicia a invenção e a criação. Certeau sugere que a história só alcança um sentido de totalidade através de imagens que jogam com a interpretação e com o conhecimento. Para ele, o historiógrafo e o literato apresentam características comuns. Tanto este como aquele recorrem à retórica em um movimento entre a constância da linguagem que representa os acontecimentos e a contingência da fabricação desses mesmos acontecimentos. Desse modo, o que se chama de "invenção", em retórica, passa a ser sinônimo de "seleção" no estudo de documentos, ocupando um lugar de interesse comum ao historiador e ao ficcionista. É uma questão de escolha de foco pelo sujeito-observador - do que será lembrado ou esquecido, incluído ou excluído na narrativa do presente e do passado. Tanto em retórica como na história essa escolha baseia-se nos efeitos da representação. Críticos e historiadores sabem que mesmo o aparentemente trivial pode, a partir de um exame mais minucioso, revelar uma estratégia capaz de apagar, marginalizar ou reprimir modelos ambivalentes. Para a história e para a literatura os critérios de seleção-invenção podem ser mais importantes que os arquivos e os textos. Seguindo essa forma de raciocinio, The Writing of History defende a semelhança entre história e ficção, e a convergência de seus objetivos. Lembra-nos de que todo fato registrado e considerado historicamente válido configura-se a partir de imagens conflitantes, e de que os registros são, na maioria das vezes, projeções mentais que carregam forte marca político-ideológica. Certeau não parte do questionamento da ocorrência histórica, mas do olhar que a observa, pois esse olhar estará sempre condicionado pelas idéias, posicionamentos, suposições e inclinações do observador, somadas às dos escritores e cronistas de outrora, responsáveis pela criação dos arquivos disponíveis. Dessa forma, os eventos narrados são tropos que "Têem" ou alegorizam o passado. Michel de Certeau, em consonância com a teoria de Platão, considera 0 "real" como o mundo primeiro e único das formas, o cosmo, a essência inspiradora da cultura, não passível de reprodução. Logo as memórias históricas seriam, em parte, fabricadas pelo pesquisador, assim como o escritor fabrica seu discurso. 


\section{EMTESE}

Belo Horizonte, V. I, p. I - 144, Dez. 1997

HALBWACHS (1990) também se apóia na tradição filosófica platônica do "mundo real, único e primeiro" para defender a hipótese de que só existe uma história. Para ele há, porém, muitas memórias coletivas que derivam das lembranças de indivíduos, enquanto membros de um grupo. Não existe memória individual. 0 que chamamos de memória individual é, na verdade, um ponto de vista da memória coletiva, e esse ponto de vista muda de acordo com o lugar que o narrador esteja ocupando, naquele momento, na memória coletiva. Com a mudança de lugar, muda também a relação entre o narrador e o grupo. 0 lugar é a moldura espacial onde a memória se desenvolve. É dertro de um espaço que a imaginação reconstrói as categorias das lembranças, sejam elas jurídicas (como, por exemplo, o direito à propriedade), econômicas (como o preço de objetos), religiosas (como o mundo sagrado e o profano), artísticas (como a invenção e a criação). Há tantas maneiras de representar espaços quantos sejam os grupos. 0 espaço é uma entidade indiferente à mudança, mas o grupo que o ocupa resiste a elas, em busca de uma continuidade histórica. A memória coletiva é sempre a memória da continuidade, embora seus limites sejam incertos, já que um grupo pode desfazer o que o outro fez. A tradição, por sua vez, é a cadeia indispensável para manter o grupo coeso, é a força que sustenta os elos. Mesmo assim, acontecem transformações inevitáveis, e a história de cada grupo renova-se, ao mesmo tempo em que se perpetua. Se o grupo se desfaz, também se desfaz a memória, sustentáculo dos traços de sua identidade. Cada grupo conta a sua história de forma diferente da contada pelos outros grupos, desencadeando a circulação de um saber próprio e móvel, em um processo de interpretação de documentos e decifração de códigos para a recriação do passado.

A solução encontrada por LEJEUNE (1989) para estabelecer um limite entre as modalidades fatuais e ficcionais do discurso está contida no conceito do que ele denomina "pacto autobiográfico". Na verdade o pacto autobiográfico é um tipo de contrato estabelecido entre autor e leitor onde o autobiógrafo se compromete - à semelhança do processo psicanalítico - não a uma exatidão histórica impossivel, mas a um esfo:ço para, através do ato autobiográfico, compreender a sua própria vida. Lejeune insiste que uma autobiografia classifica-se, em nível profundo, como um tipo especial de ficção, e que a verdade autobiográ- 
fica é tanto uma criação, quanto uma realidade (re)descoberta. Usando a distinção proposta por Emile Benveniste e Roman Jakobson entre "enunciado" e "enunciação", Lejeune enfatiza que o locus de referência na autobiografia pertence não ao nível do enunciado mas ao da enunciação, onde a identidade do autor, narrador e protagonista está colocada, textualmente, para ser entendida, de imediato, peîo leitor. A teoria do pacto autobiográfico defende que a autobiografia é uma modalidade de escrita e uma modalidade de leitura, e que a estrutura da narrativa é fundamental no processo da auto-representação. Ao determinar a atitude do leitor no ato da recepção, o pacto autobiográfico assemelha-se ao que Derrida denomina "protocolo de leitura". A preocupação de Lejeune com o problema da sinceridade autobiográfica ilustra, de modo exemplar, as dificuldades que a arte referencial enfrenta, pois, se a autobiografia e a história são tipos de escrita produzidos em circunstâncias especiais e dispensados de fidelidade ao fato, elas (autobiografia e história) correm o risco de perderem seu status como gênero e de serem englobadas na ficção.

NOTAS

1. O título da revista aib: Auto/Biography Studies, publicada pelo Hall Center for the Humanities, da University of Kansas em Lawrence, serviu de modelo para a escolha da ortografia aqui adotada para a palavra "auto/biografia". Genericamente, este termo inclui todas as modalidades da escrita memorialistica. As implicações teóricas aqui referidas constituíram o parâmetro para a construção de minha tese de doutorado, intitulada Pentimentos: a auto/biografia de Lillian Hellman.

2. Utilizo-me do neologismo entre-história, aqui cunhado por mim, para explicar a posicão em que a história se encontra entre o fato em si (pretenso átomo da história) e sua reconstrução pela narrativa. 


\section{EM TEE}

Belo Horizonte, V. I, p. I - 144, Dez. 1997

\section{REFERÊNCIAS BIBLIOGRÁFICAS}

ALVES, Junia C. M. Pentimentos: a auto/biografia de Lillian Hellman. Belo Horizonte: Faculdade de Letras, 1996. 179 p. (Tese, Doutorado em Literatura Comparada).

ATKINS, G. Douglas \& MORROW, Laura (eds.). Contemporary literary theory. Amherst: The University of Massachusetts Press, 1989.

BAUDRILLARD, Jean. America. Trad. Álvaro Cabral. Rio de Janeiro: Rocco, 1986.

BAUDRILLARD, Jean. A sedução. Trad. Tania Pellegrini. Campinas: Papirus, 1991.

BAUDRILLARD, Jean. La précession des simulacres. In: Simulacres et simulations. Paris: Galilée, 1981.

BERTENS, Hans. The idea of the postmodern: a history. London: Routledge, 1995.

BHABHA, H. K. DissemiNation: time, narrative, and the margins of the modern nation. In: BHABHA, H. K. (ed.). Nation and narration. London: Routledge, 1990 .

CERTEAU, Michel de. The writing of history. Trans. Tom Conley. New York: Columbia University Press, 1988.

DERRIDA, Jacques. Freud e a cena da escritura. In: A escritura e a diferença. Trad. Maria Beatriz Marques Nizza da Silva. São Paulo: Perspectiva, 1971.

EAKIN, Paul John. Reference and the representative in american autobiography: Mary McCarthy and Lillian Hellman. In: Identità e scrittura: studi sull'autobiografia nord-americana. Roma: Bulzoni, 1988.

HALBWACHS, Maurice. A memória coletiva. Trad. Laurent Léon Schaffter. São Paulo: Vértice, 1990.

HUTCHEON, Linda. Poética do pós-modernismo: história, teoria, ficção. Trad. Ricardo Cruz. Rio de Janeiro: Imago, 1991.

JAMESON, Frederic. Espaço e imagem: teorias do pósmoderno e outros ensaios. GAZOLLA, Ana Lúcia Almeida (org.). Trad. Ana Lúcia Almeida Gazolla. Rio de Janeiro: UFRJ, 1994.

LE GOFF, Jacques. A história nova. Trad. Eduardo Brandão. São Paulo: Martins Fontes, 1993.

LEJEUNE. The autobiographical pact e The autobiographical pact (bis). In: On autobiography. Trad. Katherine Leary. Minneapolis: University of Minnesota Press, 1989. p.3-30, 119-137.

LYOTARD, Jean-François. o pós-moderno. Trad. Ricardo Corrêa Barbosa. Rio de Janeiro: José 0lympio, 1993. 